Utilising mood boards as an image

elicitation tool in qualitative research

Simon Spawforth-Jones

Leeds Arts University 


\section{Acknowledgements}

I would like to thank the men who participated in this research for giving up their time to help with the study. I would also like to thank Professor Jayne Raisborough and Dr Katherine Harrison for their continued support, advice and feedback. 


\title{
Utilising mood boards as an image elicitation tool in qualitative research
}

\begin{abstract}
The use of image elicitation methods has been recognised in qualitative research for some time however, the use of mood boards to prompt participant discussion is currently an underresearched area. This article explores the use of mood boards as a data collection method in qualitative research. Used in design disciplines mood boards allow designers to interpret and communicate complex or abstract aspects of a design brief. In this study I utilise mood boards as being part creative visual method and part image elicitation device. The use of mood boards is explained here in the context of a research project exploring masculinity and men's reflexivity. In this article I consider the benefits of utilising this method in researching reflexivity and gender before offering a critical appraisal of this method and inviting colleagues to explore how mood boards might enhance research projects involving elicitation.
\end{abstract}

\section{Introduction}

In this article I show how mood boards, a collection of images arranged and juxtaposed on a sheet, were utilised in a pilot study for a research project exploring masculinity and men's reflexivity. A technique borrowed from design disciplines, mood boards have been developed here as a way of examining men's reflexivity as it relates to their sense of self and gender. In developing this, I show that mood boards can be utilised as part creative visual method and part image elicitation tool. During this study the participants were asked to create a mood board on the topic of masculinity using images sourced from a range of men's lifestyle magazines. Creating the mood boards allowed the participants to construct a particular "image" of themselves and their sense of gender through the imagery on offer in unique and intuitive ways. As an elicitation tool, I argue that the participantcreated mood boards are an effective tool in enabling men to reflect on their lives and engage in reflexivity. There has been much debate surrounding the use of visual methods and how they relate to talk-based approaches with some championing their use instead of talk-based methods (Gauntlett, 2007) and others arguing that they are best used in combination with other methods (Buckingham, 2009; Pimlott-Wilson, 2012). By using the method both as a visual method and subsequently as a catalyst for verbal data generation I will show how visual and talk-based methods can be combined effectively.

Mood boards are best known as a technique utilised in industrial design, fashion design and interior design. Used in the early stages of the design process, it is a collection of images and/or multimedia arranged as a collage (McDonagh and Storer, 2004; Cassidy, 2011). The images used in mood boards are frequently sourced from media such as magazines, newspapers and catalogues or from web 
sources and other digital sources. Mood boards are used both as a design tool in exploring and generating ideas related to the design brief (McDonagh and Storer, 2004; Cassidy, 2011) and as a means of framing and communicating the parameters of the design project to elicit interpretation and discussion amongst the design team and stakeholders (Lucero, 2012).

Garner and McDonagh-Philp (2001) highlight that mood boards have uses in design problem solving but also problem finding. Specifically, they argue that designers benefit from the use of mood boards as a means of interpreting broad and ambiguous briefs and to establish the specific design problem. That is, they are used as a means to interpret and understand the complex, ambiguous or abstract issues involved in the project through the selection and juxtaposition of visual material. Lucero (2012) agrees with this noting that designers are charged with the task of interpreting the verbal instruction of their client and re-framing the complex and ambiguous aspects of the project. The mood board that results from this interpretative activity is then presented back to the client from which further discussions/interpretations take place. Garner and McDonagh Philp argue that mood boards 'transcend linguistic restrictions' (2001: 58) in their ability to articulate abstract and emotive concepts and suggest that the simplicity of the technique enables the designer to approach the task in a natural and intuitive manner.

Despite their simplicity, mood boards have been defined here as a creative technique as it is utilised by designers and other creatives and as it involves the construction of a unique artefact using cutand-paste collage. Creativity has many definitions however, in the context of design, Chan defines it as the capacity to generate 'meaningful new ideas, forms, performances, and interpretations' (2015: 243 my emphasis). These features are consistent with the definition presented here and indeed are useful to note when considering the technique as a qualitative method in social research. In the next section I will show how my use of mood boards builds upon existing work utilising creative visual methods and argue that when combined with talk-based approaches they can act as a form of image elicitation. In the subsequent sections I will discuss the application of mood boards as part of a pilot study on masculinity and reflexivity. Finally, I will critically discuss the use of mood boards and the contribution they make to elicitation methods.

\section{Mood boards as a research tool}

Mood boards utilised in qualitative research can be considered a creative visual method since participants are invited to create their own mood boards which then become the research data presented in visual form. Broadly, creative visual methods utilised in qualitative research are methods that ask the participants to make something using visual media, such as video editing, collage, drawing, and even Lego, in order to expressing their ideas about the research theme 
(Buckingham, 2009; Gauntlett and Holzwarth, 2006). This approach is different to methods that utilise visual tools where the media, frequently photographs and videos, are generated by the researcher as a form of data gathering (Buckingham, 2009). As such, creative visual methods present an alternative to talk-based approaches (Gauntlett, 2007) in generating participant responses. Mood boards, therefore, whilst indeed considered to be a creative technique, can also be used as a creative visual method when employed in the context of qualitative research.

The use of mood boards as a research tool, at the time of writing is limited except for Pimlott-Wilson (2012) who explores the use of mood boards in social research involving children. Pimlott-Wilson argues that mood boards and other visual methods are best when used in combination with other talk-based approaches. Nonetheless, she says that the visual methods used generated rich insights into the participants' lives and helped them to express emotions that would have been difficult with talking methods alone. She argues mood boards to be particularly advantageous owing to their simplicity and accessibility in the sense that participants are not limited by their creative or technical capacity. Pimlott-Wilson argues that this technique allows participants to 'better articulate their thoughts, feelings and abstract concepts, [...] spending less time concentrating on the actual picture, but on its often multiple meanings in their eyes' (2012: 143). She also suggests that mood boards have the benefit of versatility which is demonstrated in how her participants used the task to either represent a past experience or to express their feelings about an upcoming event.

Whilst the use of mood boards in qualitative research is limited, the use of creative visual methods broadly has been well documented particularly. Gauntlett (2006; 2007), for example, has championed the use of creative visual methods in media audience research. He argues that these methods empower participants to be able to express themselves and 'communicate, in a meaningful way, about their identities and experiences' (2006: 82). This is because they allow the participant to consider the research theme in their own time and because the tasks engage their hands, body and mind together. For these reasons, Gauntlett suggests, his participants feel more in control of the research situation and able to arrive at more considered responses. Gauntlett contrasts creative visual methods with talk-based approaches in audience research where participants are expected to respond verbally to questions with no time to reflect on the issues more fully. He demonstrates that these methods allow participants to communicate different kinds of information in a holistic way. That is, making pictures 'enable us to present information, ideas or feelings simultaneously, without the material being forced into an order or hierarchy' (2007: 183).

Buckingham (2009) argues that creative visual methods can be useful but require a much greater level of researcher reflexivity than has been applied in previous studies, including Gauntlett's. He 
argues that Gauntlett's tendency to treat these methods as 'neutral - as simply a means of enabling participants to express themselves more directly' inherently undermines considerations of power dynamics in the research situation. Buckingham (2009) also notes that even though Gauntlett criticises the limitations of talk-based approaches, he frequently relies on talk in asking participants to explain and contextualise their creative outputs. Gauntlett's investment in the expressive capabilities of creative methods 'precludes the possibility of analysis' (Buckingham, 2009: 645) and as such his analysis of the creative objects are often descriptive and 'more significantly - has to rely on what participants say' (2009: 645 his emphasis).

Both Pimlott-Wilson (2012) and Buckingham (2009) therefore, endorse the use of creative methods in conjunction with talk-based approaches. Used in this way, where participants create something and then talk about its meaning, the outputs of the participants become a sort of elicitation device whereby the output as well as the process itself provoke opinions, feelings and discussions about the research themes. The use of elicitation in qualitative research is most frequently done using photographs with other media such as video being utilised less often (Harper, 2002). Photo elicitation has been praised (Collier, 1957; Harper, 2002; Van Auken et al, 2010) for its ability to easily trigger responses to research themes that may be difficult to obtain using only interviewing. Collier also noted that participants were more amenable to the research process when images were used (1957). Harper, reviewing the uses of photo elicitation in sociology and anthropology, argues that the method has shown the capacity to tap into 'a different part of human consciousness' (2002: 23) particularly due to how images, rather than words, enhance memory recall. Although I agree that visual stimuli can open up new ways of interpreting research questions, I do not agree entirely with Harper's suggestion that they can reveal something that is hidden. Harper's approach suggests an essentialist notion of an underlying self that must be revealed by the research. However, this notion disregards the influence of the researcher and the research situation on the data that is generated. Nonetheless, I want to show through this article that image elicitation can bring about ways of constructing and articulating the self in the research situation.

In photo elicitation research the photographs themselves can be obtained from researchers, participants or from archival sources (Oliffe and Bottorff, 2007). Van Auken et al (2010), focussing in particular on "participant-driven" photo elicitation, argue that allowing participants to select the images to be used has the benefit of breaking 'barriers between researchers and subjects' because it 'de-centres the authority of the researcher' (2010: 375). Building on this idea I want to suggest that mood boards may also be utilised as an elicitation tool insofar as the mood board itself is derived through the curation of imagery selected by the participants and then acts as a catalyst for discussion. 
What I have suggested here is that although the use of mood boards in qualitative research is rare, its usage can be positioned both as a creative visual method and as a form of image elicitation when utilised in conjunction with talk-based methods. These two aspects of this method require different kinds of engagement on behalf of the participants and will produce different kinds of data. As a creative method mood boards have the advantage of requiring very little skill or expertise on behalf of the participants allowing them to engage with the themes of the research through the physical process of cutting and pasting without feeling inhibited. Additionally, the mood board allows participants to consider abstract or intangible concepts in an intuitive way and thus avoiding overrationalising and imposing hierarchies to their responses. Treating the mood board then as an elicitation device allows the participants to offer more considered explanations or interpretations of their visual material. What follows is an outline of how this combination of methods was used in a pilot study as part of a wider project on men, masculinity and identity.

\section{Research design}

The use of mood boards detailed here is part of a $\mathrm{PhD}$ research project concerning masculinity and reflexivity. Specifically, the project seeks to establish an understanding of the ways that men do reflexivity in relation to their sense of gender. My theoretical approach to masculinity draws on Connell's (XXXX) and Connell and Messerschmidt's (XXXX) work insofar as masculine identities are understood to be formed in the legitimation of or subordination to a hegemonic form of masculinity. However, recognising that the concept's significant influence within the field has, rightly or wrongly, resulted in numerous other types of masculinity to emerge (Coles, 2008; Bridges and Pascoe, 2014; Berggren, 2014) my research answers Waling's (2018) call to adopt approaches to agency and emotional reflexivity in order to redirect focus to the individual. For this I turn to reflexivity. Reflexivity is most attributed to Giddens (1991) who defines it as the process by which people continually monitor and make changes in their lives in response to knowledge about social life. However, I move away from this more commonly used theoretical model and adopt an updated approach drawing on Adams (2007) and Burkitt (2012). Adams and Burkitt both argue that Giddens' approach is too individualistic and disregards how the self is constructed in relation to others. The relationality of the self, and therefore the relationality of reflexivity, then underpins a more nuanced version of reflexivity. For Adams (2007), reflexivity is always partial arguing that Giddens' individualistic model ignores the many barriers and constraints that influence a person's agency. Relatedly, Burkitt (2012) argues that Giddens' approach is too rational and as such ignores the ways that emotions "infuse" with reflexivity. For Burkitt, emotions are 'about the way we engage and interrelate with others and with ourselves, and cannot, therefore, be separated from reflexivity' (2012). So, for this research, I focus in particular on how men's reflexivities are inherently bound 
within their relations with others (and therefore partial) and are also infused by emotions. Having established this basis, the challenge, then, was to construct a methodology that enabled the participants to engage with these reflexive processes in the research situation.

Although interviews were considered as a method for this research, I concluded that they would not adequately bring about reflexivity. By asking questions to the participants without any other stimulus I expected that many of the responses would be statements and opinions presented matter-of-factly. My interests instead were to allow reflexivity to emerge in their reflections, reactions and relations with others. A visual method, specifically mood boards, seemed to offer enough opportunity and time-frame to allow the men to intuitively construct a particular version of themselves. In response to arguments (Buckingham, 2009; Pimlott-Wilson, 2012) that creative methods are best used with talk-based methods I had decided to execute this method as part of a group discussion. Bringing a group of men together for the activity and discussion would offer the opportunity to capture how statements are constructed relationally in social interaction (Morgan, 2012) acknowledging also that the self is not something that exists in social isolation rather it is also understood to be relational (Adams, 2007; Burkitt, 2012). Buckingham also endorses the use of participant groups in social research on the basis that they reveal 'the ways in which participants define and negotiate meanings through social interaction, and thereby also perform and construct social identities' (2009: 645). Similarly, participant groups have been utilised in masculinities research (Gill et al, 2005; Allen, 2005) were noted to reveal ways that men perform or construct masculine identities through interaction.

Participants were provided with a range of men's lifestyle magazines, specifically, issues of $G Q$, Esquire, Attitude, and Men's Health, as sources of imagery for their mood boards. There were a number of reasons for making the decision to use these magazines specifically. Firstly, these magazines contained many images that could be utilised in the men's mood boards. The imagery contained in these magazines resonated well with the theme of the research in that they referenced many key areas of masculine identity and practices such as body image, grooming and sexuality. That said, each of the titles are subtly different in their content and focus. For instance, Men's Health focuses specifically on health and fitness (predominantly body sculpting) while Attitude is made for a gay male readership and as such much of the content is regarding relations between men and aspects of gay lifestyle. The distinctions in style and content of the magazines was important as they improved the chances that the men would find some content of interest to them specifically and also improve the chance the content would provoke conversation and debate amongst the group. Secondly, utilising specific titles provided a consistency across any future research sessions whereby the general image content would remain consistent from one session to another. Most importantly 
the magazines were a common knowledge amongst the men in the sense they had all had some knowledge of them. Of course, I made this decision knowing that the contents and themes that the magazines offered would inevitably have some influence on the mood boards and the statements made by the participants. However, what was important in the research was to reveal reflexive processes and these could easily be framed in relation to the magazines.

Category 2 ethical approval for this study was obtained from the Leeds Beckett University ethics committee prior to data collection. There were five participants who were originally recruited for the pilot study however, one withdrew leaving four participants who eventually took part. The men were recruited by loosely using a snowball approach. Two of the men were known to the researcher as friends-of-friends. These two men were also known to each other. The men all volunteered their time for this study and were offered refreshments during the session. Communication with the participants initially took place on Facebook Messenger in order to establish interest in the research. Further communications then took place using e-mail. The session was audio recorded and the names were anonymised using pseudonyms through the process of transcribing. Data analysis of the transcripts was done using thematic analysis (Braun and Clarke, 2006) which identified several themes related to the men's reflexivities.

During the session I positioned the group around a single table and distributed A3 card, glue and scissors. Personal information such as age, ethnicity and sexual orientation were collected from each participant at the start of the session. It was expected that this information would help to contextualise the men's responses and their mood boards. To help demonstrate what I was asking the participants to do in the research session I presented them briefly with two examples of mood boards made for design projects. The men were then asked to create their own mood board about their understanding of masculinity using imagery sourced from the magazines. I had kept the instructions for the task intentionally broad so to allow the participants to be able to approach the task in their own way.

During the making of the mood boards I steered the discussions to issues specifically concerning masculinity. The group discussions required little moderation as the magazines themselves helped to keep focus on the issue of masculinity. Some of the topics derived directly from the content of the magazines whereas other topics emerged naturally through conversations. Once each of the participants had completed the mood board task they were then asked to present their mood boards to the group. They were asked to comment on the imagery used on their mood board and explain why they were drawn to the images. During this stage the participants were invited to 
consider and explain their choices in more depth contrasting the mood board activity itself in which they were encouraged to undertake the task in quite an intuitive manner.

At the time of the study Wayne was twenty-eight years old, a straight, white British male and employed as a support worker. Ronny is white British, straight, works in sales and at the time of the study was twenty-nine years old. Dan is also white British, straight, in a sales role and was thirty years old at the time of the study. Andy was twenty-seven years old at the time of the study working as an administrator. He is Asian British and identified as bisexual. I will now deliberate over each of the participants' mood boards and the commentary and discussions that emerged in relation to the imagery in the order they were presented in the session.

\section{Wayne's mood board}

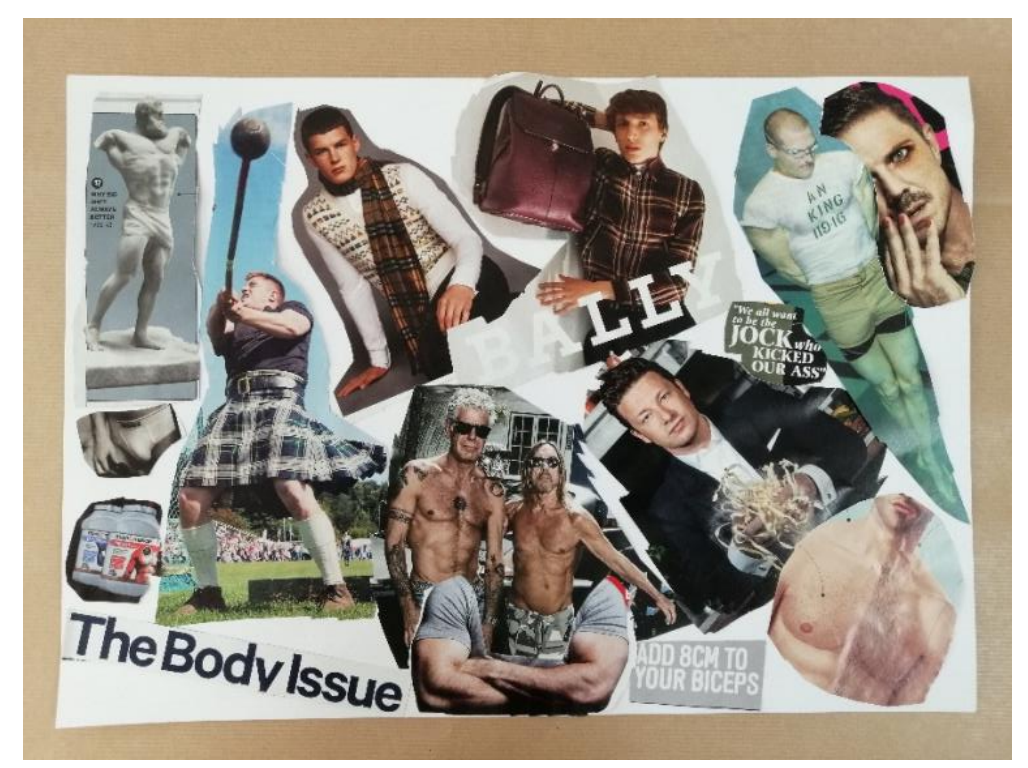

Wayne showed little reservation in discussing intimate experiences from his past with the other participants. One such discussion arose in relation to the contents of Wayne's mood board. Here, imagery from Men's Health magazine initiated a discussion amongst the men about body envy. Wayne and Ronny were open about their own experiences of body envy particularly related to their desire to achieve a certain kind of physique:

Wayne: ...I definitely notice myself kind of idolizing certain bodies in the gym or in the changing room or in magazines and stuff. I can't help it. I just can't help it.

Ronny: I do massively yeah

Wayne: Yeah

Ronny: I get body envy so bad especially watching like things as barbaric as UFC. 
Ronny: I'm starting to get into the idea of these two guys kicking the absolute fucking shit out of each [other] and me being totally fine with it and erm but also as well the body envy comes in pretty strong.

Wayne: Yeah cos those guys are in phenomenal shape.

Dan: Yeah that's also not a realistic comparison either.

Ronny: That's it. I can never get to that unless I dedicate my entire life so [...] even though I'm talking about it quite openly, I know it's so silly, but still cant help the fact that I go "oh my god imagine if I could look like that. That would be incredible."

Moderator: Do you feel the same when you see stuff in here [referring to Men's Health] or is it just UFC?

Ronny: No its definitely men's fitness like [...] its like a specimen isn't it?

Dan: Like a Yoel Romero type?

Wayne: Jesus that guys crazy!

Ronny: Christ, yeah.

Here Ronny, Wayne and Dan were engaged in a discussion about body envy and the circumstances that envy arises. In discussing their own senses of inadequacy, the notion of body envy, at least for Ronny and Wayne, is presented as an accepted fact of life. In this extract Dan and Ronny both also acknowledged that body envy is often based on unrealistic comparisons. As Ronny states, he could not achieve a particular body shape unless he dedicated his entire life to it. Ronny also establishes clear body aspirations via his engagement with UFC' stating "oh my god imagine if I could look like that." This discussion demonstrated that media images play a role in how the men articulate their emotions related to body envy and how they establish aspirations for their own bodies (Saz Rubio, 2019). That is, men are exposed to hegemonic archetypes of male bodies that are used to evaluate their own bodies. Yet the body itself and the opportunities that the men have to engage in body work establish clear limits to being able to achieve their goals .

Wayne's use of an image of Anthony Bourdain ${ }^{\text {ii }}$ and Iggy Popiii elicited a small conversation among the group regarding aging and looks. Ronny, Wayne and Dan all found it inspiring to see Bourdain in such "good shape for his age" and Ronny in particular found the notion of being a "silver fox"iv 
something to aspire to later in life. Ronny contributes his perspective that masculinity is something that is frequently associated with youth:

Wayne: I guess the last thing here; we've got two guys that are considered sex icons.

Ronny: Yeah.

Ronny: Although Iggy Pop's stomach now looks like his face.

Wayne: I'm not so much into this [points to Iggy Pop] but this guy [points to Anthony Bourdain] is in incredible shape for his age.

Dan: You know who that is though, don't you?

Ronny: Its Anthony Bourdain and Iggy Pop.

Dan: Yeah its Anthony Bourdain.

Wayne: Is it?

Ronny: He's dead.

Dan: Yeah. He killed himself.

Wayne: Oh shit.

Ronny: Yeah. He wasn't very well in the end.

Wayne: Really.

Dan: Looking at him there [points to image] he was really close towards the end of his life...

Ronny: ....and he looks fantastic. He looked unbelievable.

Dan: He looked in ridiculous shape. Do you know how he got like that? Jujitsu.

Wayne: Really. Yeah, it's just that it brings up that silver fox idea.

Others: [Nodding in agreement] 
Wayne: And that phrase is hilarious to me.

Ronny: I would love to be a silver fox.

Wayne: My girlfriend has genuinely said that she is attracted to men with grey hair. [...] I thought this was an interesting thing to be attracted towards because actually when you look at biological attraction the fittest people both mentally, with their confidence, [and] with their body; that's who people are drawn to because they're going to make the strongest genes. That's what it all comes down to but I think that we've passed that now to the point that there are people who have granny fetishes.<smiles>[C]1[CH]C=C1</smiles>

Ronny: I wanted to add that masculinity, if you think about it, sometimes feels quite like a young person's game. But the silver fox thing, that's actually quite interesting because it means that you can actually be quite masculine and attractive and when you get older in life. And actually its becoming more and more popular for guys to look after themselves longer into the future because they want to carry on that sense of masculinity.

Interestingly here, the men spend little time deliberating over the circumstances of Bourdain's suicide and focus instead on his looks and his figure. Whilst Ronny and Dan are keen to inform Wayne of Bourdain's suicide, collectively the men move quickly past this issue to a discussion of his physique. Ronny's interjection, '...and he looks fantastic. He looked unbelievable', brings forth this swift change of focus and suggests that perhaps it is difficult to reconcile being (or looking) physically healthy and simultaneously being mentally very unwell. The men's collective skirting of this issue could also be suggestive of an often discussed (Webber, 2019; Cambule, 2017; Stein, 2018) tendency for men to avoid conversations about mental health. It is apparent that, for Wayne and Ronny at least, aging has the potential to be conflictual with their ideas surrounding masculinity. Aging bodies that are nonetheless toned and muscular give the men hope that looking good and being masculine may continue further into their lives. Despite, as in Bourdian's case, that one's mental health may not fare so well. In this excerpt the men's emotions towards this issue are very much intertwined with their relations to one another. The men implicitly spur each other on which generates their positive emotional reactions to the topic of discussion

\section{Ronny's mood board}




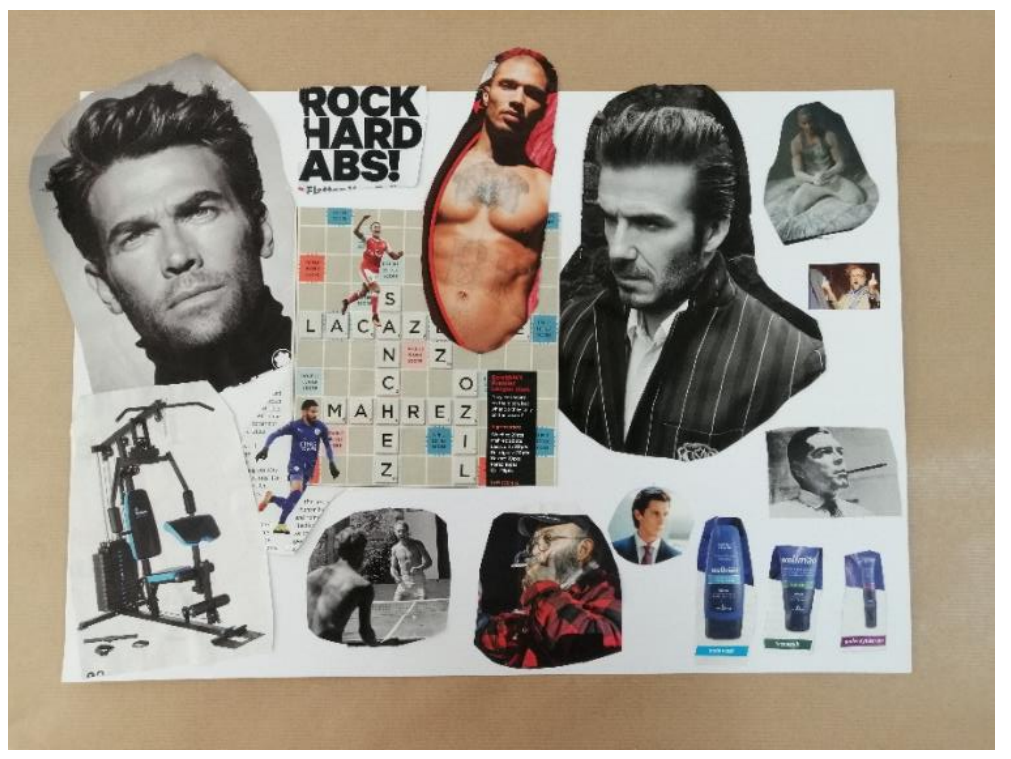

Ronny chose to represent masculinity by highlighting a paradox of caring and not caring. This sort of ambivalence echoes Robertson's (2003) study that found a common dilemma in attitudes towards health whereby men feel that they should present themselves as not caring whilst being aware that they should care. However, for Ronny, the idea of caring about one's appearance whilst also "not giving a fuck" was quintessential to his conceptualisation of masculinity. He enjoyed the imagery of men smoking and gesturing with two middle fingers in contrast to others, such as David Beckham ${ }^{v}$ and "Mont Blanc man" who apparently take considerable care and effort over their appearance:

Ronny: I also liked the imagery of smoking. I don't know what that is but like an old guy with the cigar in his mouth just screams at me. That just looks cool like masculine-wise. I don't know what it is about just a guy smoking

\section{$[\ldots]$}

I love that guy there. He just looks like he's been smoking all his life and he doesn't care [image right-of-centre at the bottom edge]. I like that idea about masculinity, you know, just this guy who is like the total paradox of this guy. This guy who looks after himself lots and I can identify with him from a masculine point of view and this guy doesn't give a fuck but he's smoking and he looks cool

\section{$[.$.}

So, I like this idea that you really care and then you don't care at all.

Wayne: Yeah. 
Ronny: I just love that idea that it could be on both sides: oh my God I really want to have rock hard abs but also I don't give a fuck.

Looking good and being attractive featured prominently in Ronny's explanation of his mood board. At times during the making of his mood board he reacted to images of men he found particularly pleasing and even suggesting that he would like to look like them. When asked to comment on how he positions himself in relation to people that he sees in media he admitted that he saw himself as quite superficial:

Ronny: I'm like the typical knobhead. So, I like David Beckham. Oh god I just gravitate towards him because he's got a really good sense of style and he has shown you can wear all these tattoos and stuff and still loads of women would kind of like [Ronny digresses] ... I love that kind of adulation where everyone kind of walks in and goes "oh my god its him", like that, I love that.

Ronny: Yeah mines very superficial. I've always known about it, it's just really superficial. It's just because when I was growing up the attention was always surrounding the guys that looked good in football kit. And I was like "oh my god". Because I was short and fat and looked like a lesbian [...] I always used to look up to footballers on the school team and think they were unbelievable. And the girls were just like "oh my god" so I always wanted that.

Here Ronny elaborates on his perspective on media imagery and particularly personalities like David Beckham and contextualises this admiration through his adolescent experiences from school. He also utilises a sort of self-deprecating humour which softens what is quite a critical admission of his own self-interests. For Ronny masculinity was about being able to invest time and energy in appearance and self-care. He used the term metrosexual to describe a sort of masculinity that he aspires to. In the next excerpt David Beckham was positioned by Ronny as being an archetypical example of metrosexuality. This follows a previous comment by Ronny which expressed an appreciation for the metrosexual label and the practices of male self-care. In the following extract the image of the Mont Blanc model elicits responses from both Wayne and Ronny who express their admiration for the attractiveness of the man in the image and particularly his hair:

Ronny: I think I've mentioned metrosexuality previously because I feel like I define more towards that wanting to make yourself look good, essentially. And that's where like David 
Beckham and Mont Blanc man [image top-left on his board] come into it because he's got great hair. Look at his hair.

Wayne: That hair is beautiful.

Ronny: That hair is gorgeous.

Moderator: He has a very stoic look as well.

Ronny: One hundred percent. Things could pass him by. He's all right he's not bothered you know.

Ronny returned to the topic of tattoos in his mood board having already credited David Beckham with making tattoos OK to have earlier in the session. He discussed how tattoos have today become, as he says, "gentrified" before expressing his own desire to get a "sleeve"vi tattoo:

I tell you what I like the idea of tattoos [in relation to] masculinity. It's kind of been, what's the word, gentrified I think a little bit. Because beforehand if you thought about tattoos it was like sailors and sailor tattoos and prison tattoos. But I really like that idea about masculinity and that's why I'm going to get a sleeve...

This is an interesting moment as Ronny reconciles any negative associations that he perceives to be related to tattoos in order to justify his appreciation of them and their potential in expressing his own masculinity. Ronny is the most reflexively open of the men. He continually generates meanings for the imagery he uses in relation to his own identity and life-history. The other men are perhaps a little more hesitant about engaging the same degree of reflexive self-monitoring.

\section{Dan's mood board}




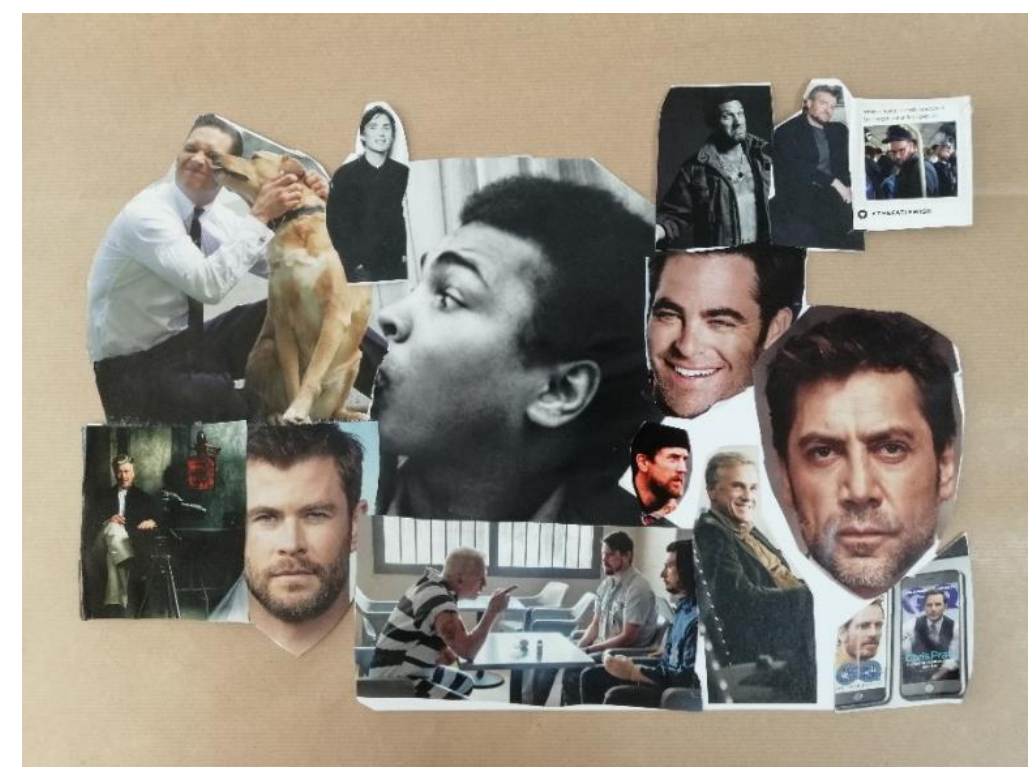

Dan's mood board focused entirely on the appropriation of celebrity imagery. He did not articulate explicitly how these images reflected his own sense of masculinity instead, he used aspects of their personalities and demeanors in framing a certain sort of idealised masculinity. Dan established a criteria for the kinds of men that he chose to present on his board. Particularly, he explained that a lot of the key people presented on his mood board have a self-deprecating personality:

Dan: Flicking through those adverts and not once did a look at one of the perfume adverts with somebody who I didn't recognize. The only time I'd ever stop and look at it was when there was somebody who I recognized so there's Tom Hardy was on one of them, I think Chris Hemsworth was on one of them. But the reasons why they ended up going in [on to the mood board] wasn't because they were on those adverts but it's because they've all got a level of that apparent male bravado, that appearance, the way that they should look, but they also have the ability to be self-deprecating. So, like Tom Hardy, I've previously mentioned, Chris Hemsworth, especially like with the way that Thor Ragnarok has really positioned what Thor should be and could be. And the whole archetype of Thor in general, like the way that he's paid off as just being one of the most powerful things in creation and then the further and further you get into it he's just this completely and utterly destroyed little individual who doesn't really know what his purpose is.

Dan: All of the guys who have wound up in here, so like Cillian Murphy, Tom Hardy, Muhammad Ali, Chris Pine, Christoph Waltz, are all very self-deprecating. They have all got 
the ability to present themselves in a certain way. You look at them [and] see a level of success but at the same time they don't make that seem like that's what they're defining purpose is. It always feels like they're doing other things [at] the same time. It's the same thing with Charlie Brooker [who] made his way up in there as well. I think Charlie Brooker is fucking ace and as far as aspirations as a human being that's kind of where I lie [...] and just got David Lynch there because he's an absolute badass.

Dan's explanation of his mood board offers a mix of aspiration and admiration. At first, he suggests that he admires a type of masculinity that he describes as having "bravado" yet self-deprecation, illustrated particularly through images of Tom Hardy vii and Chris Hemsworth viii. Yet, it is not Chris Hemsworth, the actor, that he focuses on rather it is his character, Thor, that Dan finds most interesting. The para-social connection (Klimmt et al, 2013) that he feels extends beyond the lives of the celebrities themselves and into the fictional realm of their character portrayals. Earlier in the session Dan explained his inclusion of Tom Hardy on his mood board which further highlights his para-social relationship:

Dan: [...] Tom Hardy's made his way on to my thing [mood board] twice purely because if you asked me [about] the idea of masculinity Tom Hardy's the first person that I would go to for that for that. Mainly because of what he does. So, you look at his acting roles and he jumps from one side of the spectrum all the way to the other He plays this insanely camp clone of Jean-Luc Picard in a really early Star Trek film, all the way to playing Bronson. And then the way that he [presents] himself in the public eye where he's like volunteering for dog's homes call lines and stuff like that. I just see this guy who just seems to really care and that to me is the epitome of masculinity. Not only to be the typical archetype of what a guy should look like and should act like but also be self-deprecating he's able to acknowledge that that is what it's supposed to look like but also go "nah, fuck that" at the same time.

Moderator: Is that aspirational for you too?

Dan: Well it's never really been something that I do. I don't look at him and sort of go "man, I wish I was like that guy" I look at him you sort of go "I'm really glad he's doing that".

Andy: Yeah man

Dan: It's very rare that I look at other people and see something, as far as like a physical appearance, and go "that's what I want to look like". 
Andy: Yeah, yeah, yeah.

Dan: I've just never really had that. I think it's happened to me maybe twice in my life. I remember sort of looking at Chris Hemsworth not long after I shaved my beard and going "man, I wish I got my beard back". And then I think it was a picture of Alexisonfire and I saw one of them wearing a plaid shirt and went "I'd like a plaid shirt".

Dan's explanation here is somewhat ambivalent in that he suggests Tom Hardy represents what he sees as an archetype of masculinity in both his image and his behaviour yet when asked if his ideas of Tom Hardy are aspirational he distances himself from the possibility that he may be personally influenced by media or celebrity. Of course, the caveat to this is that he confesses two circumstances that he was influenced to change his appearance. Here, again, there are clearly interweaving moments of admiration and aspiration in his explanations. And yet, Dan's reluctance to fully embrace this para-social bond with and admiration for the celebrities referenced on his mood board suggests that, although he is happy to frame his conceptualisation of masculinity through these celebrity images, his reflexivity effectively guards the uniqueness of his own identity.

\section{Andy's mood board}

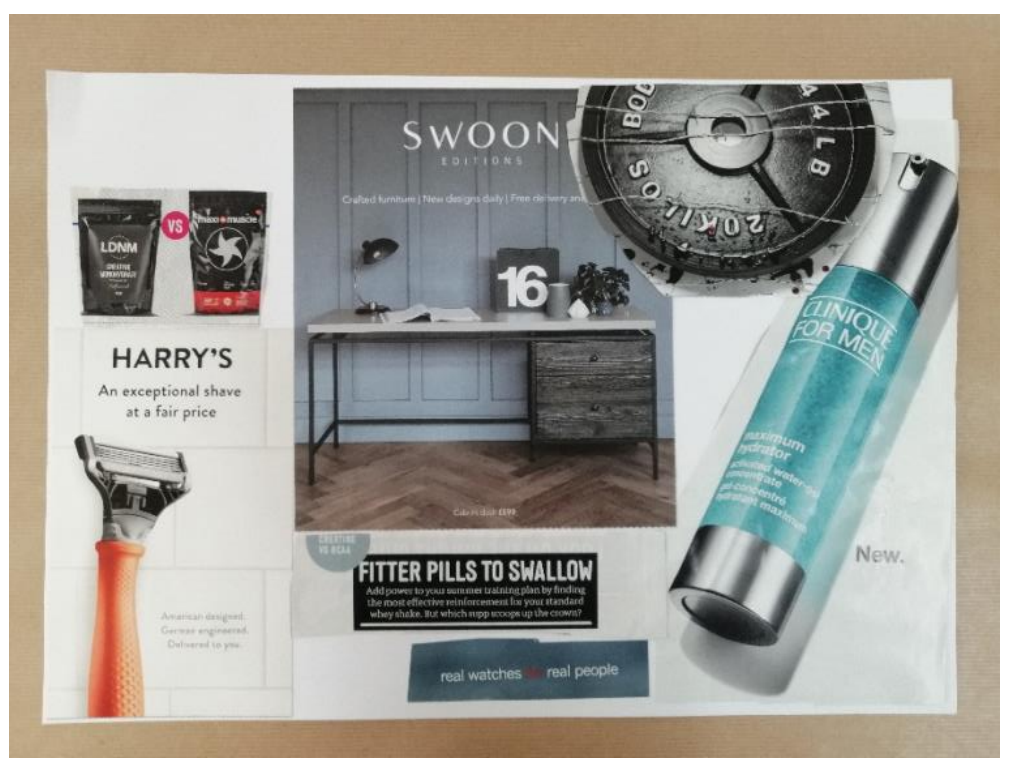

His mood board was the only one of the four that did not portray any images of people. Andy was not resistant to the study in general and was very attentive to the other men and their personal opinions on the issues discussed however, he was very critical about using label such as masculinity. For Andy, labels were cultural or commercial obsessions that detracted people from what was truly important. Throughout the session he was frequently critical of the contents of the magazines and he argued on several occasions that gender and identity politics are just ways that people try to 
make connections. Andy therefore struggled to find meaning in the magazine content that resonated with his own sense of self and his ideals. I do not see this as a negative effect of using these magazines as stimulus to the research however, because despite Andy's personal resistance, the magazines were a catalyst for his emotional reflections. In the following extract he explains that from a young age he struggled to adhere to gender expectations in the same way that he perceived others were able to:

Andy: [...] For me, from a young age, I never really felt like I fit into what was a classic definition or a desirable version of masculinity. If that makes sense. And I always thought that masculinity was always just a form of attraction game. It's always about some level of reproductive desirability that's not always been like a big drive of mine. I always felt, when I was growing up at school, that I was in a sort of odd environment for who I was at the time, if that makes sense. I never fit a lot of the bills of what girls or other guys around [that] tick boxes of desirability did. So, I've never looked at that as any sort of envy and going "god, I wish I could like do better with women, if I'd only looked like this". I've never felt any of that, that's why there's not a single person on there [on the mood board].

Unlike the other men, Andy used only images of objects on his mood board. Because he did not find personal meaning in the imagery he chose to represent masculinity as problematic. For Andy, the objects presented, taken from advertisements and article headers, represent some of the ways that men are forced to adopt restrictive identity traits and practices. In discussing his mood board Andy quickly shifts his commentary to broader issues of gender and identity politics.

Andy expressed a sustained criticism of gender labels throughout the session but was confident and self-assured about his own sense of identity despite his perception that he was different to other people. As such, Andy frequently constructed statements that effectively distanced himself from what he saw as normal opinions and behaviour. This distancing strategy was also used in relation to his own family and cultural background:

Andy: I've never really felt the gender thing because masculinity is really oddly defined culturally from how I've grown up. Boys are just thought of to be great just because they are lads and most of the support structures that exist within my family [are] run by women.[...] It is fronted by men who believe that they have got the thing sussed but most of the men in my family are either jobless alcoholics, fat, overweight and unhealthy. And actually not really good partners. But they have a certain sense of entitlement that comes with it. They are like "I'm just gonna get married and I'll fucking get my chapatis made for me" and all that kind of stuff. When really the [women] have kept a lot of it together. And I've been raised by 
women. I have a very feminine conversation style and I've never really fit in with the blokes in my family because a lot of them can't express themselves unless they are absolutely hammered. [...] They can't dance unless they are absolutely hammered, they can't be nice to each other unless they are absolutely hammered. They don't know it but the reason why they're encouraging each other to get that drunk is so they can just be vulnerable. That's all it is. They're all just trying to get to that point of connection.

Here Andy shows how his own identity and attitude towards gender has been influenced by his familial experiences. He is almost aggressive in his criticism of the men of his family and praises the women for their hard work and their influence on him growing up. Andy sustained a criticism of the magazines, labels and gender politics in general however, he spoke positively of vulnerability, connections and being free to express one's own unique identity. And although he dismissed gender as being a superficial way of finding connections, he did on some occasions negotiate his position within a masculine-feminine framework often favouring feminine, or at least less masculine.

Andy constructs a self-identity and narrative defined by resistance to commonly held masculine characteristics and practices. Andy's statements were frequently delivered with force, volume and an emotional drive that was not matched by the other men. Frequently, the other men agree with Andy, in principal, but at other times Andy's perspective towards gender politics does generate debate amongst the men. For example, Ronny and Andy debated whether masculinity and femininity are inherent human traits or socialised. This debate stemmed from an earlier discussion of masculinity and femininity that took place in relation to the contents of Wayne's mood board.

Ronny: Physicality is easily definable for me. I would say "wow she looks very masculine". And i know that's probably not right.

Andy: It's more of a descriptor but the problem is people then get hung up on what they believe masculinity means and then they project their own feelings of masculinity on themselves. Because for you to say that someone looks masculine... well what does that mean? Because if you look it up in the dictionary what masculine means everyone would dispute that definition like "that's not right". Do you know what I mean?

Ronny: I politely disagree in a sense that if you looked at a woman's rugby team would you not define that as potentially masculine? So think if you've seen for the very first time women with huge thighs.

Andy: I would characterize large thighs as a feminine trait. 
Wayne: Not when their purpose is to fucking drive through a load of other human beings.

Ronny: Yeah. A load of other women.

Andy: But like I don't have that so does that make me less masculine?

Ronny: No, because you're bringing it back to yourself and I'm not trying to bring it back to you I'm trying to ask....[Andy interrupts]

Andy: But then how can I not bring it back to myself if we don't have some sort of definition? [...] You can only use the word masculinity now in this conversation here. It just doesn't work because what I define it as is completely different to what you define it as. So for you to be just like "no, I'm talking about masculinity in terms of the physical sense". I'm like, well now the word is just becoming hollower and hollower as time goes on. Because you're like well without any sort of general definition of a word it's just nonsense. It's just a noise. When you sit in that conversation I'm like we're not speaking the same language with that word because of the connotations. The contexts of it are so blurred.

$[\ldots]$

Dan: Don't you think it can be over-analysed to a point as well?

Andy: Massively. I'm almost worried that this is too big of a point for no reason that's my issue.

Ronny: So would you look at erm a YouTuber right now who does a lot of makeup tutorials as a guy and say that's quite feminine? Or would you not? [...]

A: I would say actually, like personally, this is where it gets blurry. I would say that something like makeup this is quite, I want to say, man-made. I mean human-made. A superficial sort of extra that's kind of a result of our society. I don't know whether testosterone hormonally creates more of that competitive rough-and-tumble behaviour within men. Whereas something like doing makeup, I don't know if makeup is something that is biologically inherent to women. [Ronny interrupts]

Ronny: It definitely is. It definitely is. I mean, take that right back to the Egyptians it was definitely inherent.

Andy: But men did it as well.

Ronny: Men did it as well yeah but then it stopped. It stopped for quite a long period of time after that it wasn't always necessary. 
Here Andy and Ronny disagree on the source of commonly understood characteristics of gender. At other points in the session Dan showed support for Andy's perspective on gender as being socialised and Wayne showed similar support for Ronny's position that gender traits are innate. This excerpt demonstrates how passionately the men guard their own knowledge of gender. For these men, their lay knowledge of gender, be it innate or socialised, are tightly bound up with their identities and self, a connection that they both defend in their own way.

\section{Discussion}

Citing Chan (2015) I noted at the beginning of this article that an aspect of creativity, and therefore mood boards, is in generating new interpretations. The participants of this study were asked to create a mood board based on their understanding of what masculinity means to them. As such, by producing a mood board they are engaging in an interpretative activity constructing a particular image of themselves through the magazine sources on offer. Reflecting this, Bagnoli also found that creative methods helped to 'open up participants' interpretations of questions' (2009: 547). She also argues that 'a creative task may encourage thinking in non-standard ways, avoiding the clichés and "ready-made" answers' (2009: 566). I would support this however, based on the findings from this study, I would suggest that even though the creative task allowed the men to interpret the issue of masculinity in a non-standard way, it was still necessary for them to relay their thoughts verbally. I do not believe, however, that the participants verbal contributions were simply echoing the intended meanings of the mood boards rather, being asked to verbalize their mood boards forced the men to re-interpret what they had made and in doing so produced a new viewpoint. Although the mood boards themselves could be analysed and may offer an insight into the participants identities, without the verbal contribution there is little reliability in such an analysis and little to go on in terms of their reflexive thinking.

Combining a creative method with this form of image elicitation allowed the men to engage with the research theme in two quite different ways. I noted earlier that mood boards are produced quickly and intuitively but on the other hand, relaying the contents of their mood boards and constructing meaning verbally requires different cognitive processes. In making their mood boards the men were invited to peruse the magazines and select images that resonated with their sense of masculinity. It was apparent, perhaps with the exception of Andy, that the men did not deliberate much over their image selections and their mood board arrangements. Contrastingly, when asked to present the boards the men endeavored to rationalise their choices in a holistic way and make the imagery meaningful in relation to their lives and their sense of coherence as a masculine subject. It is this 
secondary viewpoint, elicited through being asked to re-present their mood boards, where the value in this method lies for researching men's reflexivity.

There remains a question however, of whether the men's accounts discussed here are evidence of reflexivity or simply self-reflection. For Giddens, reflexivity is distinguished from self-reflection insofar as it is a continuous revision of biographical narrative based on the knowledgeability of human agents drawn from abstract systems (1991). However, Burkitt (2012) disagrees that selfreflection is distinct from reflexivity. Burkitt argues that self-reflection precedes reflexivity (which is only understood to be particular to late modern life) and as such reflexivity is built upon a foundation of a person's ability to self-reflect. If self-reflection is understood to be an inherent aspect of reflexivity, what then remains essential to this definition of reflexivity is the notion that people monitor their lives in light of knowledge made available through abstract systems. What has been demonstrated in the accounts discussed here is the intertwining of self-reflection and reflexivity. Aligning, positioning, aspiring, resisting, adopting are all aspects of the men's reflexive processing embedded within their self-reflections.

\section{Conclusion}

I suggest here that the use of men's lifestyle magazines in this study was well placed to enable the men to engage in reflexivity. The magazines were useful practically as they were known by all the men in some capacity and as such their preconceived ideas about the magazines aided in discussions between the participants. However, they were also beneficial in drawing the men into a reflexive mode of thinking. In this way the magazines acted as a kind of common knowledge through which the participants negotiate, order and communicate aspects of their gendered identities. Due to the contents of the magazines being thematically quite broad they offered the men many opportunities to situate themselves in relation to the imagery on offer. Themes such as food/cooking, bodies, aging, and fitness were popular amongst the group and provided opportunities to frame certain aspects of themselves and their histories. Of course, the magazines and the imagery on offer certainly influenced the issues and themes discussed by the men. However, what was important for this study was not so much the thematic content of the men's accounts but the processes through which they organise and present a coherent, if not partial, image of themselves.

The use of mood boards and men's lifestyle magazines in this pilot study have been shown to elicit rich responses amongst the men showing their reflexive engagements. The mood board task was received positively by each of the men but for Andy the contents of the magazines were very much incongruous with his sense of self and morals. The collective familiarity with the magazines provided a useful vehicle for discussion yet their differing associations for the men elicited some antagonism 
amongst the men. I do not see these as negative however, as this helped to draw out differences of opinion and the personality types of the men revealing their reflexivities. The reader should note that two of the men, Ronny and Wayne, were familiar with each other and indirectly familiar with the researcher. This may well have had some baring on establishing an atmosphere where experiences, opinions and feelings could be openly exchanged. Mood boards have been used here as part of a group research activity which I have argued was appropriate in order to allow the relational aspects of reflexivity to emerge. Other researchers may consider how mood boards might also be effective when used with participants individually.

\section{References}

Adams, M. (2007) Self and social change. London: Sage.

Bagnoli (2009) 'Beyond the standard interview: the use of graphic elicitation and arts-based methods'. Qualitative Research. 9 (5): 547-570.

Braun, V. and Clarke, V. (2006) Using thematic analysis in psychology. Qualitative Research in Psychology, 3, 77-101.

Buckingham, D. (2009) 'Creative visual methods in media research: possibilities, problems and proposals'. Media, culture and society. 31 (4): 633-652.

Burkitt, I. (2012) 'Emotional Reflexivity: Feeling, Emotion and Imagination in Reflexive Dialogues'. Sociology. 46(3): 458-472.

Cassidy, T. D. (2008) 'Mood boards: Current practice in learning and teaching strategies and students' understanding of the process'. International journal of fashion design. 1 (1): 43-54.

Chan, C. (2015) Style and creativity in design. Heidelberg: Springer.

Collier, J. (1957) 'Photography in anthropology: A report on two experiments'. American anthropologist. 59: 843-859. 
Garner, S. and McDonagh-Philip, D. (2001)' Problem interpretation and resolution via visual stimuli: the use of 'mood boards' in design education'. Journal of art \& design. 20 (1): 57-64.

Gauntlett, D. and Holzwarth, P.(2006) 'Creative and visual methods for exploring identities'. Visual Studies. 21 (1): 82-91.

Gauntlett, D. (2007) Creative explorations: New approaches to identities and audiences. London: Routledge.

Giddens, A. (1991) Modernity and self-identity: Self and society in the late modern age. Cambridge: Polity Press.

Harper, D. (2002) 'Talking about pictures: A case for photo elicitation'. Visual studies. 17 (1) 13-26.

Jackson, P., Stevenson, N. And Brooks, K. (1999) Making sense of men's magazines. London: Sage.

Klimmt, C., Hartmann, T. and Schramm, H. (2013) Parasocial Interactions and Relationships. In Bryant, J. and Vorderer, P. Psychology of Entertainment. PP 291-313.

Lucero, A. (2012) 'Framing, aligning, paradoxing, abstracting, and directing: How design mood boards work'. Proceedings of the designing interactive systems conference. pp. 438-447.

McDonagh, D. And Storer, I. (2004) 'Mood boards as a design catalyst and resource: Researching an under-researched area'. The Design Journal. 7 (3): 16-31.

Morgan, D. L. (2012) 'Focus groups and social interaction'. In Gubrium, J. F., Holstein, J. A., Marvasti, A. B. And McKinney, K. D. (2012) The Sage handbook of interview research. 2nd Edition. Thousand Oaks: Sage.

Morrison, D., MacGregor, B., Svennevig, M. And Firmstone, J. (1999) Defining violence: The search for understanding. Luton: University of Luton Press.

Myers, G. And Lampropoulou, S. (2012) 'Impersonal you and stance-taking in social research interviews'. Journal of pragmatics. 44 (10): 1206-1218. 
Noor, H. (2007) 'Assertions of identities through news production: news-making among teenage Muslim girls in London and New York'. European journal of cultural studies. 10 (3): 374-209.

Oliffe, J. L. And Bottorff, J. L. (2007) 'Further than the eye can see? Photo elicitation and research with men'. Qualitative health research. 17 (6): 850-858.

Pimlott-Wilson, H. (2012) 'Visualising children's participation in research: Lego Duplo, rainbows and clouds and moodboards'. International journal of social research methodology. 15 (2): 135-148.

Van Auken, P. M., Frisvoll, S. J. And Stewart, S. T. (2010) 'Visualising community: Using participantdriven photo-elicitation for research and application'. Local environment. 15 (4): 373-388.

\footnotetext{
i Ultimate Fighting Championship (UFC) is a mixed martial arts (MMA) competition in the US.

ii Anthony Bourdain was known for being a celebrity chef and a travel documentarian. Bourdain died by suicide in 2018 while in France filming an episode of the documentary series Parts Unknown. He is featured in Wayne's mood board stood topless alongside Iggy Pop.

iii Iggy Pop is known for being a pioneer of punk music in the US. Pop is known for outrageous and chaotic stage performances. Although he did not a achieve significant commercial success, he is widely recognised within popular culture and is cited as being influential in punk and rock music.

iv Silver Fox is a slang term referring broadly to an attractive older man particularly one that has grey (silver) hair.

$\checkmark$ David Beckham was best known as a professional footballer but since then perhaps better known as a style icon and most attributed to the phrase metrosexual.

vi The word sleeve in tattooing refers to a large tattoo that covers the whole arm from the top of the shoulder to the wrist.

vii Tom Hardy is a British actor known for roles in Inception (2010) and The Dark Knight Rises (2012).

viii Chris Hemsworth is an Australian actor known for is role at Thor in a number of Marvel movies.
} 